\title{
青藏高原东部窄叶鲜卑花碳、氮、磷化学计量特征
}

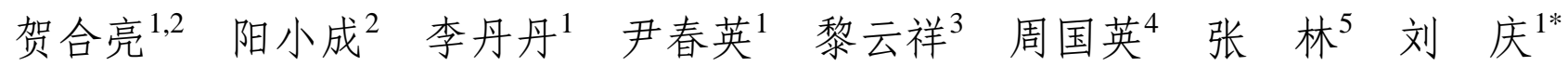

${ }^{1}$ 中国科学院成都生物研究所, 中国科学院山地生态恢复与生物资源利用重点实验室, 生态恢复与生物多样性保育四川省重点实验室, 成都 $610041 ;{ }^{2}$ 成都理工大学材料与化学化工学院, 成都 $610059 ;{ }^{3}$ 西华师范大学生命科学学院, 四川南充 637009; ${ }^{4}$ 中国科学院西北高原生物研究所, 西宁 810008 ; ${ }^{5}$ 中国科学院青藏高原研究所, 北京 100101

摘 要 为了探究青藏高原东部窄叶鲜卑花(Sibiraea angustata)灌木不同器官碳 $(\mathrm{C}) 、$ 氮 $(\mathrm{N})$ 、磷 $(\mathrm{P})$ 含量的分配格局及其生态 化学计量特征, 该文采用分层随机抽样方法布设样地, 选择16个窄叶鲜卑花灌从样地, 分别采集窄叶鲜卑花灌木根、茎、叶、 当年枝和果等植物器官样品, 并分析样品 C、N、P含量及其计量比。结果表明: C、N、P在不同器官中的含量分别表现为茎> 当年枝 $>$ 果 $>$ 根 $>$ 叶, 叶 $>$ 果 $>$ 当年枝 $>$ 茎 $>$ 根, 果 $>$ 叶 $>$ 当年枝 $>$ 根 $>$ 茎。窄叶鲜卑花各器官中C含量相对稳定, $N 、 P$ 含量变异系数较 大, 在根部的变异系数最大。在不同器官中 $\mathrm{N}: \mathrm{P}$ 的范围为7.12-12.41, 其值变化不大, $\mathrm{N}: \mathrm{P}$ 变异系数的最小值在当年枝中, 说明 $\mathrm{N}: \mathrm{P}$ 在当年枝中的内稳性较高。在该灌木植物体中 $\mathrm{C}$ 与 $\mathrm{N}$ 之间、 $\mathrm{C}$ 与 $\mathrm{P}$ 之间呈极显著的负相关关系, $\mathrm{C}$ 对 $\mathrm{N} 、 \mathrm{P}$ 具有稀释作用; $\mathrm{N}$ 与 $\mathrm{P}$ 呈极显著正相关关系, $\mathrm{N}$ 与 $\mathrm{P}$ 间具有较好的耦合协同性。分析发现: 窄叶鲜卑花不同器官 $\mathrm{C} 、 \mathrm{~N} 、 \mathrm{P}$ 化学计量特征在一定程度 上符合内稳态理论和生长速率理论, 其元素分配与器官所执行的功能密切相关; 同时指出在物种水平上应当谨慎使用生态化 学计量比来判断养分的限制情况。

关键词 窄叶鲜卑花; 生态化学计量学; 植物器官; 青藏高原

引用格式: 贺合亮, 阳小成, 李丹丹, 尹春英, 黎云祥, 周国英, 张林, 刘庆 (2017). 青藏高原东部窄叶鲜卑花碳、氮、磷化学计量特征. 植物生态学报, 41, 126-135. doi: 10.17521/cjpe.2016.0031

\section{Stoichiometric characteristics of carbon, nitrogen and phosphorus of Sibiraea angustata shrub on the eastern Qinghai-Xizang Plateau}

HE He-Liang ${ }^{1,2}$, YANG Xiao-Cheng ${ }^{2}$, LI Dan-Dan ${ }^{1}$, YIN Chun-Ying ${ }^{1}$, LI Yun-Xiang ${ }^{3}$, ZHOU Guo-Ying ${ }^{4}$, ZHANG Lin $^{5}$, and LIU Qing ${ }^{1 *}$

${ }^{1}$ Key Laboratory of Mountain Ecological Restoration and Bioresource Utilization \& Ecological Restoration Biodiversity Conservation Key Laboratory of Sichuan Province, Chengdu Institute of Biology, Chinese Academy of Sciences, Chengdu 610041, China; ${ }^{2}$ College of Material and Chemistry \& Chemical Engineering, Chengdu University of Technology, Chengdu 610059, China; ${ }^{3}$ The School of Life Science, China West Normal University, Nanchong, Sichuan 637009, China; ${ }^{4}$ Northwest Institute of Plateau Biology, Chinese Academy of Sciences, Xining 810008, China; and ${ }^{5}$ Institute of Tibetan Plateau Research, Chinese Academy of Sciences, Beijing 100101, China

\section{Abstract}

Aims Little is known about the stoichiometric characteristics of carbon (C), nitrogen (N) and phosphorus (P) in plateau shrubs across China. Sibiraea angustata is a typical and representative shrub species on the eastern QinghaiXizang Plateau, and exploring its C, N and P distribution patterns and stoichiometric properties in different organs (including root, shoot, leaf, twig and fruit) would help us better understand the mechanisms of C, N and P cycling and balance in the $S$. angustata dominated shrub ecosystem.

Methods Sixteen sampling sites were selected on the eastern Qinghai-Xizang Plateau by the stratified sampling method. The height and coverage of the dominant shrubs, latitude, longitude and altitude of the sites were recorded. Three $5 \mathrm{~m} \times 5 \mathrm{~m}$ plots were selected at each site. At least 128 biological samples of plant organs of $S$. angustata were collected and measured, respectively. The $\mathrm{C}$ and $\mathrm{N}$ concentrations of plant samples were analyzed using an elemental analyzer (2400 II CHNS). The P concentration was analyzed using the molydate/ascorbic acid method after $\mathrm{H}_{2} \mathrm{SO}_{4}-\mathrm{H}_{2} \mathrm{O}_{2}$ digestion.

Important findings The $\mathrm{C}, \mathrm{N}$ and $\mathrm{P}$ concentrations of different organs followed the order of: shoot (495.07 $\left.\mathrm{g} \cdot \mathrm{kg}^{-1}\right)>$ twig $\left(483.37 \mathrm{~g} \cdot \mathrm{kg}^{-1}\right)>$ fruit $\left(480.35 \mathrm{~g} \cdot \mathrm{kg}^{-1}\right)>\operatorname{root}\left(468.47 \mathrm{~g} \cdot \mathrm{kg}^{-1}\right)>$ leaf $\left(466.33 \mathrm{~g} \cdot \mathrm{kg}^{-1}\right)$; leaf $(22.27$ $\left.\mathrm{g} \cdot \mathrm{kg}^{-1}\right)>$ fruit $\left(19.74 \mathrm{~g} \cdot \mathrm{kg}^{-1}\right)>\operatorname{twig}\left(7.98 \mathrm{~g} \cdot \mathrm{kg}^{-1}\right)>\operatorname{shoot}\left(4.54 \mathrm{~g} \cdot \mathrm{kg}^{-1}\right)>\operatorname{root}\left(4.00 \mathrm{~g} \cdot \mathrm{kg}^{-1}\right)$ and fruit $\left(2.85 \mathrm{~g} \cdot \mathrm{kg}^{-1}\right)$

收稿日期Received: 2016-01-17 接受日期Accepted: 2016-09-21

* 通信作者Author for correspondence (E-mail: liuqing@cib.ac.cn) 
$>$ leaf $\left(1.92 \mathrm{~g} \cdot \mathrm{kg}^{-1}\right)>$ twig $\left(0.96 \mathrm{~g} \cdot \mathrm{kg}^{-1}\right)>\operatorname{root}\left(0.52 \mathrm{~g} \cdot \mathrm{kg}^{-1}\right)>$ shoot $\left(0.45 \mathrm{~g} \cdot \mathrm{kg}^{-1}\right)$, respectively. The ranges of the coefficient of variation $(\mathrm{CV})$ for $\mathrm{C}, \mathrm{N}$ and $\mathrm{P}$ concentrations were $1.71 \%-4.44 \%, 14.49 \%-25.50 \%$ and $11.46 \%-46.15 \%$, respectively. Specifically, the $\mathrm{C}$ concentration was relatively high and stable, and the maximum $C V$ values for $\mathrm{N}$ and $\mathrm{P}$ were found in roots. The $\mathrm{N}: \mathrm{P}$ value of different organs varied from 7.12-12.41 and the minimum $C V$ for $\mathrm{N}: \mathrm{P}$ was found in twig, which indicated that $\mathrm{N}: \mathrm{P}$ in twig had higher internal stability. In addition, correlation analysis indicated that the $\mathrm{C}$ concentration was significantly negatively correlated with $\mathrm{N}$ and $\mathrm{P}$ concentrations and correlation coefficients were -0.407 and -0.342 , respectively. However, $\mathrm{N}$ concentration had dramatically positive correlation with P concentration and the correlation coefficient was 0.814 . These results also could indicate that the $\mathrm{C}, \mathrm{N}$ and $\mathrm{P}$ stoichiometric characteristics in the S. angustata shrub accorded with the homeostatic mechanism and growth rate hypothesis to some extent, the distributions of $\mathrm{C}, \mathrm{N}$ and $\mathrm{P}$ concentrations were closely related to the function of the organs and it should be prudent to use ecological stoichiometric ratios to judge the condition of nutrient limitation at the species level.

Key words Sibiraea angustata; ecological stoichiometry; plant organs; Qinghai-Xizang Plateau

Citation: He HL, Yang XC, Li DD, Yin CY, Li YX, Zhou GY, Zhang L, Liu Q (2017). Stoichiometric characteristics of carbon, nitrogen and phosphorus of Sibiraea angustata shrub on the eastern Qinghai-Xizang Plateau. Chinese Journal of Plant Ecology, 41, 126-135. doi: 10.17521/cjpe.2016.0031

碳 $(\mathrm{C}) 、$ 氮 $(\mathrm{N}) 、$ 磷 $(\mathrm{P})$ 是植物的基本营养元素, 参 与细胞的结构与功能, 与植物体内的代谢过程存在 密切的联系(郭宝华等, 2014)。植物体不同功能器官 具有不同的结构物质，而不同结构物质中C、 N、P 的含量也不相同，因此，同一植物不同器官的C、N、 P含量存在差异(刘超等, 2012)。生态化学计量学是 一门新兴的交叉学科, 其结合了生物学、化学和物 理学等基本原理, 是研究生态系统能量平衡和多重 元素(主要是C、N、P)平衡的科学(曾德慧和陈广生, 2005)。关于陆地生态系统植被生态化学计量学的研 究, 近年来在国内外发展速度较快(贺金生和韩兴 国, 2010), 这些研究主要是对草地(安卓等, 2011; 宾振钧等, 2014; Song et al., 2014)、湿地(李征等, 2012; Zhang et al., 2013; Qu et al., 2014)和森林(阎恩 荣等, 2010; Moore et al., 2011; Huang et al., 2012)生 态系统的研究, 且大量的研究是针对植物叶片开展 的(吴统贵等, 2010; 阎凯等, 2011; 王凯等, 2013; 马露莎等, 2014; Xia et al., 2014)。目前, 国内有关灌 丛植物生态化学计量学的研究成果相对匮乏, 马红 红等(2014)对秦岭松栋混交林优势灌木叶片N、P的 研究指出, 优势灌木叶片 $\mathrm{N} 、 \mathrm{P}$ 的质量分数与土壤的 $\mathrm{N} 、 \mathrm{P}$ 质量分数呈正相关关系且不同优势灌木之间存 在显著差异; 牛得草等(2013)通过研究阿拉善荒漠6 种主要灌木植物叶片发现同一生活型的6种植物叶 片的C、N、P含量及其比值在整个生长季内的变化 规律不同; 李单凤等(2015)从环境分异和机制角度
对黄土高原优势灌从营养器官进行研究, 指出甘肃 和宁夏灌从群落的P资源相对贵乏。然而, 针对我国 青藏高原优势灌木物种不同器官之间C、N、P含量 的分配格局及其生态化学计量学特征的研究鲜见报 道。研究同一植物不同器官C、N、P的分配格局及 化学计量特征, 对揭示该物种的生态策略和环境适 应性具有重要的生态学和植物生理学意义。

窄叶鲜卑花(Sibiraea angustata)是青藏高原东 部高山灌从中特有的、具有代表性的物种, 分布于 我国青海南部、四川西部、西藏东南部和甘肃东南 部, 其分布范围与青藏高原东部的高寒灌从、草甸 区相当(吴宁，1998)。窄叶鲜卑花为落叶灌木, 高 2.0-2.5 m, 小枝圆柱形, 微有棱角, 叶片倒披针形, 稀长椭圆形, 顶生穗状圆雉花序, 䒿䒿果直立, 果 梗长3-5 mm, 具柔毛, 花期一般在6月, 果期8-9月 (中国科学院中国植物志编辑委员会, 1974)。目前, 对窄叶鲜卑花的研究主要集中在其化学成分及药理 活性等方面(姚莉和鞠洋，2009; 王章伟等，2014), 生态环境功能方面的研究也有报道, 李娇等(2014) 分析了窄叶鲜卑花灌丛土壤呼吸对不同施 $\mathrm{N}$ 水平的 短期响应, 吴宁 (1998)对川西北窄叶鲜卑花灌丛的 类型和生物量及其与环境因子的关系进行了研究。 但是从生态化学计量学的角度对窄叶鲜卑花的研究 未见专门报道, 基于此, 本文以分布于青藏高原东 部的窄叶鲜卑花为研究对象, 研究该灌木不同器官 C、 N、P含量及其两两比值的统计特征, 揭示青藏 
高原东部窄叶鲜卑花不同器官C、N、P的化学计量 学特征及其养分平衡和循环机制, 为我国青藏高原 灌从的高效经营及其生态功能与健康安全的维护提 供科学依据。

\section{1 材料和方法}

\section{1 研究区域与样地概况}

研究区域位于青藏高原东部( $96.08^{\circ}-102.95^{\circ} \mathrm{E}$, $29.88^{\circ}-33.27^{\circ} \mathrm{N}$, 海拔3 332-4 $212 \mathrm{~m}$ ), 地处青海南 部、四川西部、西藏东南部, 受青藏高原特殊的地 理环境和独特的地形地貌影响，该区域呈现特有的 立体气候(张新时, 1978)。窄叶鲜卑花的分布地区属 寒温带气候类型, 表现为冬长夏短、气温低、年较 差小、日较差大, 雨量充沛、分布不均, 日照充足等 气候特点。年平均气温在 $5.0{ }^{\circ} \mathrm{C}$ 以下, 年降水量在 $650.0 \mathrm{~mm}$ 以上, 降水时段主要集中在5-10月; 在11 月初土壤即开始进入冻土状态, 春秋季短促且不明 显, 冷暖季分明。植物的生长季一般为5-9月, 年日 照时间为1 850-2 $700 \mathrm{~h}$ 。

该地区冬长夏短, 植物生长期较短, 该地区的 植被具有较强的耐寒性, 能够忍耐冬季长达数月的 积雪覆盖和冻土环境(张发会等, 2008)。该地区灌丛 群落灌木层除了优势物种窄叶鲜卑花外, 还存在其 他伴生灌木物种, 包括山生柳(Salix oritrepha)、高山
绣线菊(Spiraea alpina)、金露梅(Potentilla fruticosa)、 岩生忍冬(Lonicera rupicola)、紫丁杜鹃(Rhododendron violaceum)、川滇绣线菊(Spiraea schneideri$a n a) 、$ 奇花柳(Salix atopantha)等植物。该区域草本 层物种较多, 主要有羊茅(Festuca ovina)、条纹龙胆 (Gentiana striata)、珠芽苶(Polygonum viviparum)、 紫花针茅(Stipa purpurea)等。

\section{2 样品采集}

根据窄叶鲜卑花灌从在青藏高原东部的分布情 况(表1), 采用分层随机抽样的方法布设样地, 共选 择了16个具有代表性的地段作为样地进行调查, 在 每个样点采用GPS仪和地质罗盘测定经纬度、海拔、 坡度等环境指标。

样品的采集工作选择在8-9月进行, 当地灌从 植被处于生长季中后期, 在每个样地随机设置 3 个 5 $\mathrm{m} \times 5 \mathrm{~m}$ 的样方, 重复样方两两边缘之间的最小距 离为 $5 \mathrm{~m}$, 最大距离不超过 $50 \mathrm{~m}$ 。在每个样方中, 选 取 $1 \mathrm{~m} \times 1 \mathrm{~m}$ 的小样方进行收割, 并按不同部分进行 取样(根、茎、叶、繁殖器官, 如能区分还应划分当 年枝), 所取样品要多于100 g, 采集后进行杀青处 理, 装入信封, 带回实验室做进一步处理。

\section{3 样品的处理和测定}

带回实验室的灌木植物样品用恒温烘箱在65 ${ }^{\circ} \mathrm{C}$ 条件下烘至恒质量, 取烘干的灌木样品 $(>1 \mathrm{~g})$ 用

表1 窄叶鲜卑花灌从样地基本信息

Table 1 Basic information of Sibiraea angustata dominated shrub sites

\begin{tabular}{|c|c|c|c|c|c|c|c|c|}
\hline $\begin{array}{l}\text { 样地编号 } \\
\text { Plot ID }\end{array}$ & $\begin{array}{l}\text { 调查地区 } \\
\text { Location }\end{array}$ & $\begin{array}{l}\text { 纬度 } \\
\text { Latitude } \\
(\mathrm{N})\end{array}$ & $\begin{array}{l}\text { 经度 } \\
\text { Longitude } \\
\text { (E) }\end{array}$ & $\begin{array}{l}\text { 海拔 } \\
\text { Altitude } \\
(\mathrm{m})\end{array}$ & $\begin{array}{l}\text { 灌木层高度 } \\
\text { Height of shrub } \\
\text { layer }(\mathrm{m})\end{array}$ & $\begin{array}{l}\text { 灌木层盖度 } \\
\text { Coverage of shrub } \\
\text { layer (\%) }\end{array}$ & $\begin{array}{l}\text { 坡度 } \\
\text { Slope } \\
\text { aspect }\left(^{\circ}\right) \\
\end{array}$ & $\begin{array}{l}\text { 坡位 } \\
\text { Slope position }\end{array}$ \\
\hline 1 & 四川理塘 Litang, Sichuan & $29.88^{\circ}$ & $100.33^{\circ}$ & 3980 & 1.10 & 80 & 10 & 中部 Middle part \\
\hline 2 & 四川理塘 Litang, Sichuan & $30.08^{\circ}$ & $100.35^{\circ}$ & 4064 & 0.80 & 60 & 10 & 下部 Lower part \\
\hline 3 & 四川色达 Sêrtar, Sichuan & $31.85^{\circ}$ & $100.73^{\circ}$ & 3535 & 0.40 & 70 & 21 & 中下部 Mid-lower part \\
\hline 4 & 四川炉霍 Luhuo, Sichuan & $31.62^{\circ}$ & $100.23^{\circ}$ & 3847 & 0.70 & 70 & 20 & 中部 Middle part \\
\hline 5 & 四川甘孜 Garzê, Sichuan & $31.45^{\circ}$ & $99.97^{\circ}$ & 4212 & 0.85 & 75 & 19 & 中下部 Mid-lower part \\
\hline 6 & 四川道孚 Dawu, Sichuan & $30.88^{\circ}$ & $101.23^{\circ}$ & 3332 & 1.20 & 40 & 14 & 中下部 Mid-lower part \\
\hline 7 & 四川小金 Xiaojin, Sichuan & $31.70^{\circ}$ & $102.32^{\circ}$ & 4034 & 2.20 & 70 & 15 & 中上部 Mid-upper part \\
\hline 8 & 四川马尔康 Barkam, Sichuan & $31.90^{\circ}$ & $102.65^{\circ}$ & 3709 & 3.10 & 70 & 20 & 中部 Middle part \\
\hline 9 & 四川阿坝 Aba, Sichuan & $32.72^{\circ}$ & $102.01^{\circ}$ & 3813 & 1.20 & 60 & 15 & 中部 Middle part \\
\hline 10 & 四川壤塘 Xiangtang, Sichuan & $32.30^{\circ}$ & $101.07^{\circ}$ & 3909 & 1.10 & 70 & 15 & 中部 Middle part \\
\hline 11 & 四川金川 Jinchuan, Sichuan & $31.53^{\circ}$ & $101.68^{\circ}$ & 3748 & 2.20 & 50 & 5 & 下部 Lower part \\
\hline 12 & 四川松潘 Songpan, Sichuan & $33.02^{\circ}$ & $102.95^{\circ}$ & 3344 & 1.05 & 80 & 0 & 中上部 Mid-upper part \\
\hline 13 & 青海久治 Jiuzhi, Qinghai & $33.27^{\circ}$ & $100.62^{\circ}$ & 3738 & 0.90 & 70 & 28 & 下部 Lower part \\
\hline 14 & 青海玉树 Yushu, Qinghai & $33.03^{\circ}$ & $96.87^{\circ}$ & 4053 & 1.20 & 65 & 39 & 中下部 Mid-lower part \\
\hline 15 & 青海囊谦 Nangqên, Qinghai & $31.88^{\circ}$ & $96.88^{\circ}$ & 4034 & 1.05 & 45 & 35 & 中下部 Mid-lower part \\
\hline 16 & 西藏洛隆 Lhorong, Xizang & $30.73^{\circ}$ & $96.08^{\circ}$ & 4198 & 0.70 & 32 & 10 & 下部 Lower part \\
\hline
\end{tabular}


杯式粉碎机进行粗粉碎, 过 10 目篮混匀, 颗粒过大 而未过篎的粗样品继续进行粗粉碎, 如此循环直到 完全过篮(对于木质坚硬的样品可先用木锤敲碎, 然后再进行粗粉碎), 然后用冷冻混合球磨仪将粗 粉碎样品 $(>1$ g)进行细粉碎, 过100目篮, 装袋标号, 用于实验分析。采用 $\mathrm{C} / \mathrm{N}$ 元素分析仪 (2400II CHNS/O, PerkinElmer, Boston, USA)测定灌木样品 C、N含 量, 使用酸溶-钼锑抗比色法测定灌木样品 $\mathrm{P}$ 的含量。

\section{4 计算和统计方法}

数据的计算和统计分析主要采用Excel 2007、 SPSS 20.0等软件, 在Origin 8.5软件中制作插图。首 先, 采用Excel 2007软件对C、N、P含量及其比值等 原始数据的平均值、标准偏差和变异系数(变异系数 $=$ 标准偏差/平均值 $\times 100 \%$ )等统计指标进行计算; 再 使用SPSS 20.0 统计软件对相关数据进行单因素方 差分析; 最后在SPSS 20.0中对C、N、P含量及其比 值进行Pearson相关性分析。

\section{2 结果和分析}

\section{1 不同器官 $C 、 N 、 P$ 化学计量特征}

青藏高原东部窄叶鲜卑花不同器官 $\mathrm{C} 、 \mathrm{~N} 、 \mathrm{P}$ 含 量的描述性统计值可见表 2 。从表 2 可知, C含量在不
同器官中的分配情况表现为: 茎>当年枝 $>$ 果 $>$ 根> 叶; $N$ 含量的分配情况为: 叶 $>$ 果 $>$ 当年枝 $>$ 茎 $>$ 根; $P$ 的分配情况为: 果 $>$ 叶 $>$ 当年枝 $>$ 根 $>$ 茎。茎中C含量 显著高于叶和根 $(p<0.05)$; 叶片中 $\mathrm{N}$ 和 $\mathrm{P}$ 含量显著 高于茎、根和当年枝 $(p<0.05)$; 果中 $\mathrm{P}$ 的含量也显著 高于其他器官 $(p<0.05)$ 。C的平均含量在各器官中 的变化范围为466.33-495.07 $\mathrm{g} \cdot \mathrm{kg}^{-1}$, 各器官中C含 量的最大值与最小值之间的差值不到 $30 \mathrm{~g} \cdot \mathrm{kg}^{-1}$, 不 同器官C含量的变异系数均小于5\% (1.71\%-4.44\%); $\mathrm{N}$ 含量在各器官中的变化范围为4.00-22.27 g. $\mathrm{kg}^{-1}$; 不同器官 N含量的变异系数变化范围为 $14.49 \%-$ $25.50 \%$ 。P含量在各器官中的变化范围为 $0.45-2.86$ $\mathrm{g} \cdot \mathrm{kg}^{-1} ; \mathrm{P}$ 含量在不同器官的变异系数变化范围为 $11.46 \%-46.15 \%$ 。在根部 N、P的变异系数最大, 其值 分别为 $25.50 \%$ 和 $46.15 \%$ 。由此可知, 窄叶鲜卑花不 同器官C含量相对稳定, 而N、P含量变异较大, 三者 的变异性表现为: $\mathrm{C}<\mathrm{N}<\mathrm{P}$ 。

青藏高原东部窄叶鲜卑花不同器官 C: $N 、 C: P$ 和 $\mathrm{N}: \mathrm{P}$ 的比值大小和描述性统计值见表 3 。从表3可知, $\mathrm{C}: \mathrm{N}$ 在叶和果两器官中的数值较小且不存在显著差 异 $(p>0.05)$, 分别为 $21.89 \pm 4.90 、 24.82 \pm 4.26$; C: $N$ 在茎和根中的数值比较相近 $(p>0.05)$, 分别为 $113.72 \pm 23.02 、 123.92 \pm 28.78$; 根和茎中C: $N$ 数值显

表2 窄叶鲜卑花不同器官碳 $(C)$ 、氮 $(N)$ 、磷 $(P)$ 含量特征

Table 2 Content of carbon (C), nitrogen (N) and phosphorus (P) of Sibiraea angustata shrub in different organs

\begin{tabular}{|c|c|c|c|c|c|c|c|}
\hline 元素指标 Element & 不同器官 Different organ & $n$ & MIN $\left(\mathrm{g} \cdot \mathrm{kg}^{-1}\right)$ & $\operatorname{MAX}\left(\mathrm{g} \cdot \mathrm{kg}^{-1}\right)$ & $\mathrm{M}\left(\mathrm{g} \cdot \mathrm{kg}^{-1}\right)$ & $S D\left(\mathrm{~g} \cdot \mathrm{kg}^{-1}\right)$ & $C V(\%)$ \\
\hline \multirow[t]{5}{*}{$\mathrm{C}$} & 叶 Leaf & 31 & 451.16 & 487.92 & $466.33^{\mathrm{a}}$ & 9.58 & 2.05 \\
\hline & 果 Fruit & 16 & 443.82 & 494.54 & $480.35^{\mathrm{ab}}$ & 21.33 & 4.44 \\
\hline & 当年枝 Twig & 22 & 471.58 & 496.38 & $483.37^{\mathrm{b}}$ & 8.28 & 1.71 \\
\hline & 茎 Shoot & 30 & 475.34 & 520.68 & $495.07^{\mathrm{b}}$ & 10.29 & 2.08 \\
\hline & 根 Root & 29 & 407.51 & 500.62 & $468.47^{\mathrm{a}}$ & 19.46 & 4.15 \\
\hline \multirow[t]{5}{*}{$\mathrm{N}$} & 叶 Leaf & 31 & 14.14 & 32.84 & $22.27^{c}$ & 4.65 & 20.88 \\
\hline & 果 Fruit & 16 & 17.08 & 23.25 & $19.74^{\mathrm{c}}$ & 2.86 & 14.49 \\
\hline & 当年枝 Twig & 22 & 5.16 & 11.02 & $7.98^{\mathrm{b}}$ & 2.03 & 25.44 \\
\hline & 茎 Shoot & 30 & 2.95 & 6.77 & $4.54^{\mathrm{a}}$ & 0.97 & 21.37 \\
\hline & 根 Root & 29 & 2.69 & 6.91 & $4.00^{\mathrm{a}}$ & 1.02 & 25.50 \\
\hline \multirow[t]{5}{*}{$\mathrm{P}$} & 叶 Leaf & 31 & 1.07 & 4.10 & $1.92^{\mathrm{c}}$ & 0.65 & 33.85 \\
\hline & 果 Fruit & 16 & 2.37 & 3.33 & $2.85^{\mathrm{d}}$ & 0.40 & 15.09 \\
\hline & 当年枝 Twig & 22 & 0.83 & 1.16 & $0.96^{\mathrm{b}}$ & 0.11 & 11.46 \\
\hline & 茎 Shoot & 30 & 0.22 & 0.78 & $0.45^{\mathrm{a}}$ & 0.16 & 35.56 \\
\hline & 根 Root & 29 & 0.23 & 1.14 & $0.52^{\mathrm{a}}$ & 0.24 & 46.15 \\
\hline
\end{tabular}

$C V$, 变异系数; $M$, 平均值; MAX, 最大值; MIN, 最小值; $n$, 子样本容量; $S D$, 标准偏差。在同一元素平均值列中的不同小写字母表示不同器官元素含 量差异显著 $(p<0.05)$ 。

$C V$, coefficient of variation; M, mean; MAX, maximum; MIN, minimum; $n$, subsample number; $S D$, standard deviation. Different small letters in the same element and mean column indicate the significant difference in the different organs $(p<0.05)$. 
表3 窄叶鲜卑花不同器官碳 $(\mathrm{C})$ 、氮 $(\mathrm{N})$ 、磷 $(\mathrm{P})$ 比值特征

Table 3 The ratio of carbon (C), nitrogen (N) and phosphorus (P) of Sibiraea angustata shrub in different organs

\begin{tabular}{llrrrrrr}
\hline 元素比值 Element ratio & 不同器官 Different organ & $n$ & MIN & MAX & M & $S D$ & $C V(\%)$ \\
\hline C:N & 叶 Leaf & 31 & 13.74 & 32.99 & $21.89^{\mathrm{a}}$ & 4.90 & 22.38 \\
& 果 Fruit & 16 & 19.84 & 28.75 & $24.82^{\mathrm{a}}$ & 4.26 & 17.16 \\
& 当年枝 Twig & 22 & 44.14 & 96.18 & $64.16^{\mathrm{b}}$ & 16.83 & 26.23 \\
& 茎 Shoot & 30 & 71.70 & 167.96 & $113.72^{\mathrm{c}}$ & 23.02 & 20.24 \\
& 根 Root & 29 & 63.72 & 174.63 & $123.92^{\mathrm{c}}$ & 28.78 & 23.22 \\
$\mathrm{~N}: \mathrm{P}$ & 叶 Leaf & 31 & 4.15 & 16.91 & $12.41^{\mathrm{c}}$ & 3.11 & 25.06 \\
& 果 Fruit & 16 & 5.28 & 9.42 & $7.12^{\mathrm{a}}$ & 1.93 & 27.11 \\
& 当年枝 Twig & 22 & 5.87 & 9.88 & $8.21^{\mathrm{a}}$ & 1.42 & 17.30 \\
& 茎 Shoot & 30 & 5.96 & 17.32 & $10.80^{\mathrm{b}}$ & 2.80 & 25.93 \\
& 根 Root & 29 & 2.86 & 14.97 & $8.74^{\mathrm{a}}$ & 3.11 & 35.58 \\
C:P & 叶 Leaf & 31 & 112.11 & 454.22 & $266.18^{\mathrm{b}}$ & 82.09 & 30.84 \\
& 果 Fruit & 16 & 147.97 & 186.92 & $170.30^{\mathrm{a}}$ & 17.54 & 10.30 \\
& 当年枝 Twig & 22 & 418.12 & 570.63 & $507.29^{\mathrm{c}}$ & 51.77 & 10.21 \\
& 茎 Shoot & 30 & 629.05 & 2219.58 & $1235.46^{\mathrm{d}}$ & 437.02 & 35.37 \\
& 根 Root & 29 & 421.11 & 2089.60 & $1070.28^{\mathrm{d}}$ & 439.16 & 41.03
\end{tabular}

$C V$, 变异系数; M, 平均值; MAX, 最大值; MIN, 最小值; $n$, 子样本容量; $S D$, 标准偏差。在平均值列中的不同小写字母表示不同器官间差异显著 $(p<$ $0.05)$ 。

$C V$, coefficient of variation; M, mean; MAX, maximum; MIN, minimum; $n$, subsample number; $S D$, standard deviation. Different small letters in the mean column indicate the significant difference in the different organs $(p<0.05)$.

著高于当年枝、叶和果 $(p<0.05)$ N $: \mathrm{P}$ 的数值在各 器官中相对比较稳定, 其平均值的变化范围为 7.12-12.41; 最大值在叶中, 为 $12.41 \pm 3.11$, 最小值 在果中, 为 $7.12 \pm 1.93$; 叶和茎中 $\mathrm{N}: \mathrm{P}$ 数值显著高于 当年枝、根和果 $(p<0.05)$ 。C:P的数值在各器官中的 变化巨大, 其平均值的变化范围为170.301235.46 ; 最小值是在果中, 为 $170.30 \pm 17.54$, 最大 值是在茎中, 为 $1235.46 \pm 437.02$; 根和茎中 $\mathrm{C}: \mathrm{P}$ 的 数值显著高于当年枝、叶和果 $(p<0.05)$ 。

\subsection{C、 N、P含量及其比值间的相关性}

通过SPSS 20.0统计分析软件对窄叶鲜卑花植 株C、N、P含量及其比值进行Pearson相关分析, 结 果(表4)表明, C含量与 $\mathrm{N} 、 \mathrm{P}$ 含量总体上均呈极显著 的负相关关系 $(p<0.01)$, 其相关系数分别为 -0.407 、 -0.342 。而 $\mathrm{N}$ 含量与 $\mathrm{P}$ 含量之间呈极显著的正相关关 系 $(p<0.01)$, 其相关系数为 0.814 , 相关性较强, 这 在一定程度上反映了 $\mathrm{N} 、 \mathrm{P}$ 在植物体内的耦合程度较 高。C:N数值与C呈极显著的正相关关系 $(p<0.01)$, 与 $\mathrm{N}$ 呈极显著的负相关关系 $(p<0.01)$, 相关系数分 别为 $0.374 、-0.901 。 \mathrm{C}: \mathrm{P}$ 数值与 $\mathrm{C} 、 \mathrm{C}: \mathrm{N}$ 值呈极显著 的正相关关系 $(p<0.01)$, 其相关系数分别为 0.432 、 0.833 ; 与 $\mathrm{N} 、 \mathrm{P}$ 呈极显著的负相关关系 $(p<0.01)$, 相 关系数分别为 $-0.746 、-0.796$, 负相关性较强, 产生
表4 碳 $(\mathrm{C})$ 、氮 $(\mathrm{N})$ 、磷 $(\mathrm{P})$ 含量及其比值之间的相关系数(Pearson检验) Table 4 The correlation coefficient among carbon $(\mathrm{C})$, nitrogen $(\mathrm{N})$, phosphorus (P) content and their ratios (Pearson test)

\begin{tabular}{|c|c|c|c|c|c|c|}
\hline 项目 Item & C & $\mathrm{N}$ & $\mathrm{P}$ & C:N & $\mathrm{C}: \mathrm{P}$ & $\mathrm{N}: \mathrm{P}$ \\
\hline C & 1 & & & & & \\
\hline $\mathrm{N}$ & $-0.407^{* *}$ & 1 & & & & \\
\hline$P$ & $-0.342^{* *}$ & $0.814^{* *}$ & 1 & & & \\
\hline $\mathrm{C}: \mathrm{N}$ & $0.374^{* *}$ & $-0.901^{* *}$ & $-0.802^{* *}$ & 1 & & \\
\hline $\mathrm{C}: \mathrm{P}$ & $0.432^{* *}$ & $-0.746^{* *}$ & $-0.796^{* *}$ & $0.833^{* *}$ & 1 & \\
\hline $\mathrm{N}: \mathrm{P}$ & -0.001 & $0.366^{* *}$ & -0.118 & $-0.276^{* *}$ & $0.213^{*}$ & 1 \\
\hline
\end{tabular}

此现象的原因是 $P$ 作为 $C: P$ 值的除数, $P$ 值越大, $C: P$ 值越小, 故两者极显著负相关, 而 $\mathrm{N}$ 与 $\mathrm{P}$ 极显著正相 关，从而 $\mathrm{C}: \mathrm{P}$ 与 $\mathrm{N}$ 极显著负相关。在植物体内 $\mathrm{N}: \mathrm{P}$ 与 $\mathrm{N}$ 含量呈极显著的正相关关系 $(p<0.01)$, 而其与 $\mathrm{P}$ 含 量的相关性不显著 $(p>0.05)$, 在一定程度上说明在 窄叶鲜卑花中 $\mathrm{N}: \mathrm{P}$ 值的变化主要由 $\mathrm{N}$ 含量变化决定。

\section{3 讨论}

\section{1 窄叶鲜卑花灌木生态化学计量特征}

目前, 国内外对陆地生态系统化学计量学的研 究主要集中在对植物群落叶片C、N、P含量及其计 量学特征的研究, 而对植物物种不同器官C、N、P 
含量及其比值特征的研究相对较少。本文对窄叶鲜 卑花不同器官中C、N、P含量的分配格局进行研究, 结果表明, C在各器官中的含量高且相对稳定, N、P 含量较低且变异系数都较大, $N$ 的变异系数小于 $\mathrm{P}$ (表 2), 原因可能是 $\mathrm{C}$ 是构成植物骨架的基本结构物质, 且为植物新陈代谢、生长发育和繁殖等生理活动提 供能源的物质, 需求量大, 所以在植物体内含量高 且变异小; Vitousek (1998)通过N、P的施肥试验, 发 现 $\mathrm{N}$ 含量被植物控制在较窄的范围内, 故 $\mathrm{N}$ 含量在各 器官中的变异性小于P, 本研究的结果与Vitousek的 试验结论一致。 $\mathrm{N} 、 \mathrm{P}$ 含量的变异系数的最大值都位 于根部(表2), 这可能是由植物体中 $\mathrm{N}$ 和 $\mathrm{P}$ 的来源引起 的，即植物通过根系从土壤中吸收和利用有效的 N、

$\mathrm{P}$, 因不同土壤环境中有效 $\mathrm{N} 、 \mathrm{P}$ 含量存在较大差异, 故造成根系对 $N 、 P$ 的吸存量具有较大差异。

不同植物器官C、N、P含量的差异不仅受植物 的基本生理过程需求的影响, 而且受相应器官的组 织结构和功能分化的影响(Minden \& Kleyer, 2014)。 灌木等木质植物的茎是植物的支撑、输导器官, 该器 官组织主要是由木质素、纤维素等富含 $\mathrm{C}$ 的多糖物质 组成(Freudenberg \& Neish, 1968), 植物茎的这一结 构性质决定其C浓度较高, 因此C在窄叶鲜卑花茎中 的浓度最高。叶片既是植物的同化器官, 也是植物 重要的养分储存器官, 而茎、枝和根作为养分的吸 收和输送通道, 较少储存养分(李合生, 2002), 因而 导致窄叶鲜卑花叶片的 $\mathrm{N}$ 和 $\mathrm{P}$ 含量显著地高于茎、根 和当年枝 $(p<0.05)$ 。采集果实对其 $\mathrm{C} 、 \mathrm{~N} 、 \mathrm{P}$ 含量进 行分析, 结果显示, 果中 $\mathrm{P}$ 的含量显著高于其他器 官 $(p<0.05)$; $\mathrm{N}$ 的含量与叶中的含量相近 $(p>0.05)$, 但是显著高于当年枝、茎和根中的含量 $(p<0.05)$ 。 由于此次采样集中在 8 月中下旬, 此时为窄叶鲜卑 花灌木的果期, 窄叶鲜卑花灌木为了促进果实的成 熟、储备营养等需要大量的蛋白质物质, 故使 $\mathrm{N}$ 含量 较高; 植物果实是遗传器官, 其中含有大量的核酸, 而 $\mathrm{P}$ 是核酸的主要构成元素, 故 $\mathrm{P}$ 在果中的含量最 高, 这也进一步表明了元素在不同器官中的含量分 配与该器官所执行的功能及植物的生长期密切相关 (Niklas \& Cobb, 2005)。

C、 $\mathrm{N} 、 \mathrm{P}$ 是生物体基本的组成元素, 生物体的 生长过程实质上是对元素的积聚与相对比例的调节 过程(曾冬萍等, 2013)。Sterner和Elser (2002)认为, 生物体C、 $\mathrm{N} 、 \mathrm{P}$ 比值与生长率有很强的关系, 在此
基础上, 产生了生长速率理论, 即生物体的快速生 长需要大量的蛋白质酶, 也需要大量核糖体RNA合 成蛋白质, 由于核糖体RNA中含有大量的P, 蛋白 质酶中含有大量的 $\mathrm{N}$, 从而使得生长率高的生物和 新陈代谢速率快的器官具有较低的 C: $N 、 C: P$ 和 $N: P$ 。 在窄叶鲜卑花不同器官中, 叶和果 $\mathrm{C}: \mathrm{N}$ 和 $\mathrm{C}: \mathrm{P}$ 的数值 显著低于其他器官 $(p<0.05), \mathrm{N}: \mathrm{P}$ 在果中最小, 这是 因为采样是在该灌木生长季的后期, 此时也是叶和 果新陈代谢速率较快的时期, 表明了不同器官C、

$\mathrm{N} 、 \mathrm{P}$ 比值特征在一定程度上符合生态化学计量学的 生长速率理论。生态化学计量学内稳态理论认为有 机体的元素组成比值是动态平衡的, 有机体存在一 个相对稳定的C、N、P比值关系(曾德慧和陈广生, 2005), 窄叶鲜卑花不同器官 $\mathrm{N}: \mathrm{P}$ 值在一个相对较小 的范围内分布, 在一定程度上反映了 $\mathrm{N}: \mathrm{P}$ 在该灌木 中具有内在的稳定性。

通过对窄叶鲜卑花C、N、P含量相关分析发现: C 与 $\mathrm{N} 、 \mathrm{P}$ 呈极显著的负相关关系 $(p<0.01)$ (表 4 ), 在植 物体中 C与 $\mathrm{N} 、 \mathrm{P}$ 一般呈负相关性是高等陆生植物 C、 N、P计量的普遍规律(Sterner \& Elser, 2002), 在窄叶 鲜卑花中这一规律得到进一步体现, 此规律可以把 植物体中的基本元素C比作溶液的溶剂, 把 $N 、 P$ 比作 溶液的溶质, 即 $\mathrm{C}$ 对 $\mathrm{N} 、 \mathrm{P}$ 有一定的稀释作用, 可以把 此规律称之为 $C$ 对 $N$ 、P的 “稀释效应”。植物中的 $N$ 和 $\mathrm{P}$ 是协同元素, 一般呈正相关关系(Wright et al., 2005), 本研究表明, 窄叶鲜卑花植株体内 $\mathrm{N}$ 与 $\mathrm{P}$ 呈极 其显著的正相关关系 $(p<0.01)$ (表4), 这一结果与烤 烟(杨梅等, 2015)、长白山森林不同演替阶段植物(胡 耀升等, 2014)、中国东部南北样带不同功能群植物 (任书杰等, 2007)等C、N、P化学计量特征的研究结 果相一致。

\section{2 窄叶鲜卑花叶片化学计量特征及其养分分析}

叶片是植物通过光合作用获取能源和光合产物 的主要器官, 研究其C、N、P化学计量特征具有重 大意义。研究表明, 青藏高原东部窄叶鲜卑花叶片 中的C含量(466.33 g. kg ${ }^{-1}$ )与Elser等(2000)对全球492 种陆地植物叶片研究所得 $\mathrm{C}$ 含量 $\left(464 \mathrm{~g} \cdot \mathrm{kg}^{-1}, p>\right.$ 0.05)极为接近; 与我国其他植物相关研究相比, 窄 叶鲜卑花叶片 C含量也处于较高水平, 高于亚热带 的浙江天童山植物(450 g. $\mathrm{kg}^{-1}, p>0.05$ )(阎恩荣等, 2010)和中国草地生态系统(438 $\left.\mathrm{g} \cdot \mathrm{kg}^{-1}, p>0.05\right)(\mathrm{He}$ et al., 2008), 显著高于阿拉善荒漠典型植物(379.01 
$\mathrm{g} \cdot \mathrm{kg}^{-1}, p<0.05$ )(张珂等, 2014)和黄土高原优势灌从 植物(421.40 g. $\mathrm{kg}^{-1}, p<0.05$ )(李单凤等, 2015), 说明 青藏高原东部窄叶鲜卑花叶片的有机化合物含量较 高, 具有较高的C储存能力。

从植物养分需求角度来看, 植物需要的多种营 养元素里 $N 、 P$ 尤为重要, 是限制植物生长和繁殖等 生理活动的重要因素(阿布里孜·阿不都热合曼等, 2015), 它们既是植物体内许多重要有机化合物的 组分, 同时又以多种方式参与植物体内各种代谢过 程。中国陆生植物叶片 $\mathrm{N}$ 含量与全球范围内的植物 叶片 $\mathrm{N}$ 含量较为接近(Han et al., 2005), 但叶片中P 含量显著低于全球陆生植物的测定值(Elser et al., 2000)。此外, 李单凤等(2015)对黄土高原优势灌从 研究发现C:P、N:P值分别为411.46和20.81, 指出黄 土高原优势灌丛的限制性元素是 $\mathrm{P}$ 。本研究中窄叶 鲜卑花叶片 $\mathrm{N}: \mathrm{P}$ 值为 12.41 , 显著低于黄土高原优势 灌从植物, 与全球植物极为接近 $(12.60, p>0.05)$ (Elser et al., 2000)。而本研究中叶片 $\mathrm{N} 、 \mathrm{P}$ 含量 $(\mathrm{N}$, $22.27 \mathrm{~g} \cdot \mathrm{kg}^{-1}$; P, $\left.1.92 \mathrm{~g} \cdot \mathrm{kg}^{-1}\right)$ 均显著高于中国陆生植 物(N, $\left.18.6 \mathrm{~g} \cdot \mathrm{kg}^{-1} ; \mathrm{P}, 1.21 \mathrm{~g} \cdot \mathrm{kg}^{-1} ; p<0.05\right)($ Han et al., 2005)和全球植物(N, $17.7 \mathrm{~g} \cdot \mathrm{kg}^{-1} ; \mathrm{P}, 1.58 \mathrm{~g} \cdot \mathrm{kg}^{-1} ; p<$ 0.05)(Elser et al., 2000), 且窄叶鲜卑花叶片 $\mathrm{P}$ 浓度也 显著高于黄土高原优势灌丛 $\left(\mathrm{P}, 1.20 \mathrm{~g} \cdot \mathrm{kg}^{-1}, p<\right.$ $0.05)$ 。尽管窄叶鲜卑花叶片 N:P值较低, 但我们认为 窄叶鲜卑花叶片具有较高的 $\mathrm{N} 、 \mathrm{P}$ 含量, 其生长很可 能不受 $\mathrm{N} 、 \mathrm{P}$ 限制。较高的窄叶鲜卑花叶片 $\mathrm{N} 、 \mathrm{P}$ 含 量来源于肥沃的土壤, 前期对窄叶鲜卑花灌从土壤 N、P含量的研究结果(贺合亮等, 2015)表明, 窄叶鲜 卑花灌从 0-10 cm层土壤营养元素 $\left(\mathrm{N}, 6.27 \mathrm{~g} \cdot \mathrm{kg}^{-1} ; \mathrm{P}\right.$, $\left.1.13 \mathrm{~g} \cdot \mathrm{kg}^{-1}\right)$ 远远高于黄土高原优势灌从 $0-10 \mathrm{~cm}$ 层 土壤 $\left(\mathrm{N}, 0.108 \mathrm{~g} \cdot \mathrm{kg}^{-1} ; \mathrm{P}, 0.54 \mathrm{~g} \cdot \mathrm{kg}^{-1}\right.$ )(李单凤等, 2015), 但土壤 $N: P$ 分析显示 $P$ 具有成为限制元素的 趋势(贺合亮等, 2015), 这与植物叶片养分限制的分 析存在一定差异。因此, 在肥沃的土壤和某些具有 较高养分含量的物种中使用生态化学计量学 N:P值 进行养分限制性判断应当谨慎, 因为相关养分限制 诊断指标的敏感性和适用性因研究对象不同而存在 差异(曾冬萍等, 2013)。故要准确评价土壤 $N$ 、P是否 为限制性养分, 不仅要比较 $\mathrm{N}: \mathrm{P}$ 值, 还要对 $\mathrm{N}$ 和 $\mathrm{P}$ 含 量及其有效性进行比较; 想要真实而准确地反映不 同物种在环境中养分的限制情况, 除了要分析叶片 $\mathrm{N}: \mathrm{P}$ 值外, 还应当分析该物质叶片 $\mathrm{N} 、 \mathrm{P}$ 含量并结合
相应的施肥试验做进一步的营养诊断。

本研究对青藏高原东部窄叶鲜卑花不同营养器 官的C、N、P化学计量特征进行了研究, 研究发现: 窄叶鲜卑花不同器官中C、N、P含量及其分配与该 器官所执行的功能和所处的生长期密切相关; 该灌 木不同器官 C、N、P计量特征在一定程度上符合生 态化学计量学的内稳态理论和生长速率理论; 在该 植物体中, $C$ 与 $N$ 或 $P$ 极显著负相关, $C$ 对 $N 、 P$ 具有稀释 效应, N和P极显著正相关性, 两者耦合程度较高; 青 藏高原东部窄叶鲜卑花灌从土壤肥沃, 窄叶鲜卑花 灌木叶片 C、N、P含量较高, 使用土壤和灌木叶片 $\mathrm{N}: \mathrm{P}$ 指标分析该物种养分限制情况存在一定差异, 故用化学计量比在肥沃的土壤和物种水平判断养分 限制性情况应谨慎。此外, 本文对窄叶鲜卑花这一 物种生长季后期 C、N、P的分配和计量特征进行了 研究, 缺少物种间、群落水平和季节动态变化分析, 随着全球变化, 尤其是气候变暖、 $\mathrm{N}$ 沉降的进行等, 灌从等陆地生态系统将受到巨大影响, 陆地植被生 态化学的元素平衡状况和相关计量指标对全球变 暖、 $\mathrm{N}$ 沉降等全球变化是如何响应的, 有待进一步深 入研究, 为此我们下一步的重点工作是研究该灌从 生态系统化学计量特征的季节动态变化及对温度升 高、N沉降等全球变化的响应机理。

基金项目中国科学院战略性先导科技专项 (XDA05050303)、科技部科技基础性工作专项 (2015FY110300)、国家自然科学基金(31570476、 31400424)和中国科学院西部之光(Y4C2021)。

\section{参考文献}

Abliz A, Lü GH, Zhang XN, Gong YM (2015). Carbon, nitrogen and phosphorus stoichiometry of photosynthetic organs across Ebinur Lake Wetland Natural Reserve of Xinjiang, Northwest China. Chinese Journal of Ecology, 34, 2123-2130. (in Chinese with English abstract) [阿布里 孜·阿不都热合曼, 吕光辉, 张雪妮, 公延明 (2015). 新 疆艾比湖流域植物光合器官碳、氮、磷生态化学计量特 征. 生态学杂志, 34, 2123-2130.]

An Z, Niu DC, Wen HY, Yang Y, Zhang HR, Fu H (2011). Effects of $\mathrm{N}$ addition on nutrient resorption efficiency and $\mathrm{C}: \mathrm{N}: \mathrm{P}$ stoichiometric characteristics in Stipa bungeana of steppe grasslands in the Loess Plateau, China. Chinese Journal of Plant Ecology, 35, 801-807. (in Chinese with English abstract) [安卓, 牛得草, 文海燕, 杨益, 张洪荣, 傅华 (2011). 氮素添加对黄土高原典型草原长芒草氮 磷重吸收率及C:N:P化学计量特征的影响. 植物生态学 
报, 35, 801-807.]

Bin ZJ, Wang JJ, Zhang WP, Xu DH, Cheng XH, Li KJ, Cao DH (2014). Effects of $\mathrm{N}$ addition on ecological stoichiometric characteristics in six dominant plant species of alpine meadow on the Qinghai-Xizang Plateau, China. Chinese Journal of Plant Ecology, 38, 231-237. (in Chinese with English abstract) [宾振钧, 王静静, 张文鹏, 徐当会, 程雪寒, 李柯杰, 曹德吴 (2014). 氮肥添加对 青藏高原高寒草甸6个群落优势种生态化学计量学特征 的影响. 植物生态学报, 38, 231-237.]

Elser JJ, Fagan WF, Denno RF, Dobberfuhl DR, Folarin A, Huberty A, Iterland S, Kilham SS, Mcauley E, Schulz KL, Siemann EH, Sterner RW (2000). Nutritional constraints in terrestrial and freshwater food webs. Nature, 408, 578580.

Editorial Committee of Flora of China, Chinese Academy of Sciences (1974). Flora of China (Volume 36). Science Press, Beijing. 70-71. (in Chinese) [中国科学院中国植物 志编辑委员会 (1974). 中国植物志(第三十六卷). 科学 出版社, 北京. 70-71.]

Freudenberg K, Neish AC (1968). Constitution and Biosynthesis of Lignin. Springer-Verlag, Berlin. 199.

Guo BH, Liu GL, Fan SH, Du MY, Su WH (2014). Distribution patterns and stoichiometry characteristics of $\mathrm{C}, \mathrm{N}, \mathrm{P}$ in Phyllostachys edulis forests of different productivity levels. Scientia Silvae Sinicae, 50(6), 1-9. (in Chinese with English abstract) [郭宝华, 刘广路, 范少辉, 杜满 义, 苏文会 (2014). 不同生产力水平毛竹林碳氮磷的分 布格局和计量特征. 林业科学, 50(6), 1-9.]

Han WX, Fang JY, Guo D, Zhang Y (2005). Leaf nitrogen and phosphorus stoichiometry across 753 terrestrial plant species in China. New Phytologist, 168, 377-385.

He JS, Wang L, Dan FBF, Wang XP, Ma WH, Fang JY (2008). Leaf nitrogen:phosphorus stoichiometry across Chinese grassland biomes. Oecologia, 155, 301-310.

Huang WJ, Zhou GY, Liu JX, Zhang DQ, Xu ZH, Liu SZ (2012). Effects of elevated carbon dioxide and nitrogen addition on foliar stoichiometry of nitrogen and phosphorus of five tree species in subtropical model forest ecosystems. Environmental Pollution, 168, 113-120.

He HL, Yang XC, Wang D, Sun YY, Yin CY, Li T, Li YX, Zhou GY, Zhang L, Liu Q (2015). Ecological stoichiometric characteristics of soil carbon, nitrogen and phosphorus of Sibiraea angustata shrub in eastern Qinghai-Tibetan Plateau. Chinese Journal of Applied and Environmental Biology, 21, 1128-1135. (in Chinese with English abstract) [贺合亮, 阳小成, 王东, 孙誉育, 尹春 英, 李婷, 黎云祥, 周国英, 张林, 刘庆 (2015). 青藏高 原东部窄叶鲜卑花灌丛土壤 $\mathrm{C} 、 \mathrm{~N} 、 \mathrm{P}$ 生态化学计量学特 征. 应用与环境生物学报, 21, 1128-1135.]

He JS, Han XG (2010). Ecological stoichiometry: Searching for unifying principles from individuals to ecosystems. Chinese Journal of Plant Ecology, 34, 2-6. (in Chinese) [贺金 生, 韩兴国(2010). 生态化学计量学: 探索从个体到生 态系统的统一化理论. 植物生态学报, 34, 2-6.]

Hu YS, Yao XY, Liu YH (2014). N and P stoichiometric traits of plant and soil in different forest succession stages in Changbai Mountains. Chinese Journal of Applied Ecology, 25, 632-638. (in Chinese with English abstract) [胡耀升, 么旭阳, 刘艳红 (2014). 长白山森林不同演替阶段植物 与土壤氮磷的化学计量特征. 应用生态学报, 25, 632638.]

Li DF, Yu SL, Wang GX, Fang WW (2015). Environmental heterogeneity and mechanism of stoichiometry properties of vegetative organs in dominant shrub communities across the Loess Plateau. Chinese Journal of Plant Ecology, 39, 453-465. (in Chinese with English abstract) [李单凤, 于顺利, 王国勋, 方伟伟 (2015). 黄土高原优 势灌从营养器官化学计量特征的环境分异和机制. 植 物生态学报, 39, 453-465.]

Li HS (2002). Modern Plant Physiology. Higher Education Press, Beijing, 96-100. (in Chinese) [李合生 (2002). 现 代植物生理学. 高等教育出版社, 北京. 96-100.]

Li J, Yin CY, Zhou XB, Wei YH, Qiao G, Liu Q (2014). Effects of nitrogen addition on soil respiration of Sibiraea angustata shrub in the eastern margin of Qinghai-Tibetan Plateau. Acta Ecologica Sinica, 34, 5558-5569. (in Chinese with English abstract) [李娇, 尹春英, 周晓波, 魏宇 航, 高巧, 刘庆 (2014). 施氮对青藏高原东缘窄叶鲜卑 花灌丛土壤呼吸的影响. 生态学报, 34, 5558-5569.]

Li Z, Han L, Liu YH, An SQ, Leng X (2012). C, N and P stoichiometric characteristics in leaves of Suaeda salsa during different growth phase in coastal wetlands of China. Chinese Journal of Plant Ecology, 36, 1054-1061. (in Chinese with English abstract) [李征, 韩琳, 刘玉虹, 安树青, 冷欣 (2012). 滨海盐地碱蓬不同生长阶段叶片 C、N、P化学计量特征. 植物生态学报, 36, 1054-1061.]

Liu C, Wang Y, Wang N, Wang GX (2012). Advances research in plant nitrogen, phosphorus and their stoichiometry in terrestrial ecosystems: A review. Chinese Journal of Plant Ecology, 36, 1205-1216. (in Chinese with English abstract) [刘超, 王洋, 王楠, 王根轩 (2012). 陆地生态 系统植被氮磷化学计量研究进展. 植物生态学报, 36, 1205-1216.]

Ma HH, Hou L, Dou YX, Zhang SX, Yang AD, Tian RX (2014). Stoichiometric characteristics of nitrogen and phosphorous in leaves of dominant shrub species in pine-oak mixed forest in the Qinling Mountains. Journal of Northeast Forestry University, 42(11), 35-38. (in Chinese with English abstract) [马红红, 侯琳, 窦艳星, 张硕 新, 杨安定, 田瑞选 (2014). 秦岭松栎混交林优势灌木 
叶片N、P化学计量特征. 东北林业大学学报, 42(11), 35-38.]

Ma LS, Chen YN, Zhang XR, Yang JJ, An SS (2014). Characteristics of leaf ecological stoichiometry of Robinia pseudoacacia in Loess Plateau. Research of Soil and Water Conservation, 21(3), 57-61. (in Chinese with English abstract) [马露莎, 陈亚南, 张向茹, 杨佳佳, 安 韶山 (2014). 黄土高原刺槐叶片生态化学计量学特征. 水土保持研究, 21(3), 57-61.]

Minden V, Kleyer M (2014). Internal and external regulation of plant organ stoichiometry. Plant Biology, 16, 897-907.

Moore TR, Trofymow JA, Prescott CE, Titus BD (2011). Nature and nurture in the dynamics of $\mathrm{C}, \mathrm{N}$ and $\mathrm{P}$ during litter decomposition in Canadian forests. Plant and Soil, 339, 163-175.

Niklas KJ, Cobb ED (2005). N, P, and C stoichiometry of Eraanthis hyemalis (Ranunculaceae) and the allometry of plant growth. American Journal of Botany, 92, 1256-1263.

Niu DC, Li Q, Jiang SG, Chang PJ, Fu H (2013). Seasonal variations of leaf $\mathrm{C}: \mathrm{N}: \mathrm{P}$ stoichiometry of six shrubs in desert of China's Alxa Plateau. Chinese Journal of Plant Ecology, 37, 317-325. (in Chinese with English abstract) [牛得草, 李茜, 江世高, 常佩静, 傅华 (2013). 阿拉善 荒漠区6种主要灌木植物叶片C:N:P化学计量比的季节 变化. 植物生态学报, 37, 317-325.]

Qu FZ, Yu JB, Du SY, Li YZ, Lü XF, Ning K, Wu HF, Meng L (2014). Influences of anthropogenic cultivation on C, N and $\mathrm{P}$ stoichiometry of reed-dominated coastal wetlands in the Yellow River Delta. Geoderma, 236, 227-232.

Ren SJ, Yu GR, Tao B, Wang SQ (2007). Leaf nitrogen and phosphorus stoichiometry across 643 terrestrial plant species in NSTEC. Environmental Science, 28, 2665-2673. (in Chinese with English abstract) [任书杰, 于贵瑞, 陶 波, 王绍强 (2007). 中国东部南北样带654种植物叶片 氮和磷的化学计量学特征研究. 环境科学, 28, 26652673.]

Song ZL, Liu HY, Zhao FJ, Xu CY (2014). Ecological stoichiometry of N:P:Si in Chinese grasslands. Plant and Soil, 380, 165-179.

Sterner RW, Elser JJ (2002). Ecological Stoichiometry: The Biology of Elements from Molecules to the Biosphere. Princeton University Press, Princeton. 1-20.

Vitousek PM (1998). Foliar and litter nutrients, nutrient resorption, and decomposition in Hawaiian Metrosideros polymorpha. Ecosystems, 1, 401-407.

Wright IJ, Reich PB, Cornelissen JHC, Falster DS, Garnier E, Hikosaka K, Lamont BB, Lee W, Oleksyn J, Osada N, Poorter H, Villar R, Warton DI, Westoby M (2005). Assessing the generality of global leaf trait relationships. New Phytologist, 166, 485-496.

Wang K, Wu HY, Lu H, Xu DY, Li N (2013). Leaf stoichiometric properties of garden tree species in Fuxin city. Arid Zone Research, 30, 236-241. (in Chinese with English abstract) [王凯, 吴祥云, 卢慧, 徐东洋, 李娜 (2013). 阜新市主要园林树种叶片生态化学计量特征. 干旱区研究, 30, 236-241.]

Wang ZW, Xu XH, Chen XT, Yu SS, Liu HD, Lin LG, Li B (2014). Chemical constituents from the aerial part of Sibiraea angustata. Journal of Chinese Medicinal Materials, 37, 57-60. (in Chinese with English abstract) [王章伟, 徐 向红, 陈笑天, 橡石山, 刘宏栋, 林利光, 李斌 (2014). 窄叶鲜卑花地上部分化学成分研究. 中药材, 37 , 57-60.]

Wu N (1998). The community types and biomass of Sibiraea angustata scrub and their relationship with environmental factors in northwestern Sichuan. Acta Botanica Sinica, 40, 860-870. (in Chinese with English abstract) [吴宁 (1998). 川西北窄叶鲜卑花灌从的类型和生物量及其与环境因 子的关系. 植物学报, 40, 860-870.]

Wu TG, Wu M, Liu L, Xiao JH (2010). Seasonal variations of leaf nitrogen and phosphorus stoichiometry of three herbaceous species in Hangzhou Bay coastal wetlands, China. Chinese Journal of Plant Ecology, 34, 23-28. (in Chinese with English abstract) [吴统贵, 吴明, 刘丽, 萧 江华 (2010). 杭州湾滨海湿地 3 种草本植物叶片 N、P化 学计量学的季节变化. 植物生态学报, 34, 23-28.]

Xia CX, Yu D, Wang Z, Xie D (2014). Stoichiometry patterns of leaf carbon, nitrogen and phosphorous in aquatic macrophytes in eastern China. Ecological Engineering, 70, 406-413.

Yan ER, Wang XH, Guo M, Zhong Q, Zhou W (2010). C:N:P stoichiometry across evergreen broad-leaved forests, evergreen coniferous forests and deciduous broad-leaved forests in the Tiantong region, Zhejiang Province, eastern China. Chinese Journal of Plant Ecology, 34, 48-57. (in Chinese with English abstract) [阎恩荣，王希华，郭明， 仲强, 周武 (2010). 浙江天童常绿阔叶林、常绿针叶林 与落叶阔叶林的 C:N:P化学计量特征. 植物生态学报, 34, 48-57.]

Yan K, Fu DG, He F, Duan CQ (2011). Leaf nutrient stoichiometry of plants in the phosphorus-enriched soils of the Lake Dianchi watershed China. Chinese Journal of Plant Ecology, 35, 353-361. (in Chinese with English abstract) [阎凯, 付登高, 何峰, 段昌群 (2011). 滇池流 域富磷区不同土壤磷水平下植物叶片的养分化学计量 特征. 植物生态学报, 35, 353-361.]

Yang M, Wang QQ, Yuan DG, Li QQ, Zeng J, Luo Q, Lan XM, Tang J (2015). C, N, P stoichiometry traits of different flue-cured tobacco organs at different growth stages. Chinese Journal of Eco-Agriculture, 23, 686-693. (in Chinese with English abstract) [杨梅, 王昌全, 袁大刚, 
李启权, 曾建, 罗茜, 兰兴梅, 唐杰 (2015). 不同生长 期烤烟各器官C、N、P生态化学计量学特征. 中国生态 农业学报, 23, 686-693.]

Yao L, Ju Y (2009). Effects of Sibiraea augustata on digestive system. Chinese Journal Integrated Traditional Western Medicine Digestion, 17, 376-378. (in Chinese with English abstract) [姚莉, 鞠洋 (2009). 窄叶鲜卑花促消 化作用的实验研究. 中国中西医结合消化杂志, 17, 376- 378.]

Zeng DH, Chen GS (2005). Ecological stoichiometry: A science to explore the complexity of living systems. Acta Phytoecologica Sinica, 29, 141-153. (in Chinese with English abstract) [曾德慧, 陈广生 (2005). 生态化学计 量学: 复杂生命系统奥秘的探索. 植物生态学报, 29, 141-153.]

Zeng DP, Jiang LL, Zeng CS, Wang WQ, Wang C (2013). Reviews on the ecological stoichiometry characteristics and its applications. Acta Ecologica Sinica, 33, 54845492. (in Chinese with English abstract) [曾冬萍, 蒋利玲, 曾从盛, 王维奇, 王纯 (2013). 生态化学计量学特征及 其应用研究进展. 生态学报, 33, 5484-5492.]

Zhang FH, He F, He YP, Fan H, Jiang TL (2008). The influencing factors and protection of biodiversity in western Sichuan. Journal of Sichuan Forestry Science and
Technology, 29(6), 46-51. (in Chinese with English abstract) [张发会, 何飞, 何亚平, 禁华, 降廷伦 (2008). 川西生物多样性的影响因素及其保护对策. 四川林业 科技, 29(6), 46-51.]

Zhang K, He MZ, Li XR, Tan HJ, Gao YH, Li G, Han GJ, Wu YY (2014). Foliar carbon, nitrogen and phosphorus stoichiometry of typical desert plants across the Alashan Desert. Acta Ecologica Sinica, 34, 6538-6547. (in Chinese with English abstract) [张珂, 何明珠, 李新荣, 谭会娟, 高艳红, 李刚, 韩国君, 吴杨杨 (2014). 阿拉善荒漠典 型植物叶片碳、氮、磷化学计量特征. 生态学报, 34 , 6538-6547.]

Zhang ZS, Song XL, Lu XG, Xue ZS (2013). Ecological stoichiometry of carbon, nitrogen, and phosphorus in estuarine wetland soils: Influences of vegetation coverage, plant communities, geomorphology, and seawalls. Journal of Soils Sediments, 13, 1043-1051.

Zhang XS (1978). The plateau zonality of vegetation in Xizang. Acta Botanica Sinica, 20, 140-149. (in Chinese with English abstract) [张新时 (1978). 西藏植被的高原地带 性. 植物学报, 20, 140-149.]

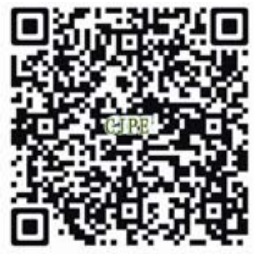

植物生态学报官网

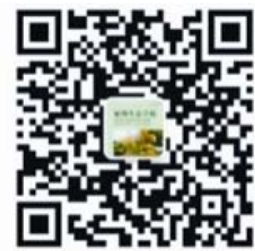

微信订阅号

期刊及学科

相关信息发布

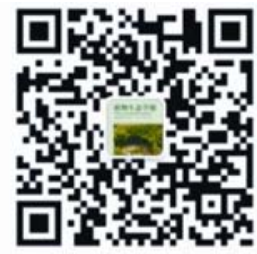

微信服务号

稿件状态查询

全文检索汶览 